\title{
Intravitreal Dexamethasone Implant (Ozurdex) in Coats' Disease
}

\author{
Ali Osman Saatci Hasan Can Doruk Aylin Yaman \\ Department of Ophthalmology, Dokuz Eylul University, Izmir, Turkey
}

\author{
Key Words \\ Coats' disease $\cdot$ Dexamethasone implant $\cdot$ Laser photocoagulation $\cdot$ Ranibizumab
}

\begin{abstract}
We injected an intravitreal dexamethasone implant in two eyes of 2 pediatric patients with Coats' disease in addition to other treatment modalities, such as intravitreal ranibizumab injection and indirect laser photocoagulation. In both eyes, intraocular pressure moderately rose in a temporary fashion. The dexamethasone implant seems to be a valuable addition to the armamentarium of treatment options for Coats' disease as it necessitates fewer injections than anti-VEGF injections and thereby fewer sessions of general anesthesia in the pediatric population.

(c) 2013 S. Karger AG, Basel
\end{abstract}

\section{Introduction}

Coats' disease is an idiopathic, retinal telangiectasia characterized by dilated, smaller-tomedium sized blood vessels with an irregular caliber and with intraretinal and/or subretinal exudation without appreciable retinal or vitreal traction $[1,2]$. The disease is usually unilateral (95\%), occurs mainly in males (75\%), and the majority of patients are diagnosed in the first or second decades of life. The primary goal of the treatment is to eradicate all abnormal vasculature and ablate areas of nonperfusion to promote resolution of intraretinal and subretinal exudation to preserve the vision and globe [2,3]. Photocoagulation of telangiectasia is usually the preferred technique over cryotherapy when there is little or no subretinal fluid. However, adjunctive treatment modalities such as intravitreal anti-VEGF agents and/or steroids may be employed to improve anatomic and visual outcome in cases with a significant amount of subretinal fluid [4]. Here, we report our experience with an intravitreal dexamethasone implant as an adjunct to other treatment modalities in 2 pediatric cases with Coats' disease. 
Saatci et al.: Intravitreal Dexamethasone Implant (Ozurdex) in Coats' Disease

\section{Case Presentation}

Case 1

A 12-year-old boy who had stage 3a Coats' disease and a history of a severe visual decline in OD was referred to us for treatment. On examination, visual acuity was counting fingers at $2 \mathrm{~m}$ in OD and 10/10 in OS. The anterior segment was unremarkable, with normal intraocular pressure in both eyes. While the left fundus was normal, there was considerable exudation involving the posterior pole, almost forming a macular plug and a slight epiretinal membrane in OD (fig. 1a). Extensive peripheral retinal vascular telangiectasia was also evident. Fluorescein angiography demonstrated wide areas of peripheral nonperfusion and dilated vessels of the lightbulb hyperfluorescence type (fig. 1b). In addition to two sessions of indirect laser photocoagulation 3 months apart, five consecutive monthly 0.05-mg ranibizumab injections were given under general anesthesia at each occasion. As the visual prognosis seemed poor due to submacular exudate plaque, we decided to inject an Ozurdex implant and discussed this option with the family. Upon acceptance of the patient's family, an intravitreal Ozurdex injection was carried out under general anesthesia without any complication (fig. 2a). A temporary rise in intraocular pressure reaching a level of $32 \mathrm{~mm} \mathrm{Hg}$ was noted 5 weeks after the injection, which was successfully managed with an antiglaucomatous medication. One year after the Ozurdex injection, visual acuity was counting fingers at $2 \mathrm{~m}$ due to fibrotic macular scarring, and intraocular pressure was normal (fig. $2 \mathrm{~b}$ ).

Case 2

A 7-year-old boy was sent to our clinic because of left exotropia and decreased visual acuity in OS. On examination, visual acuity was $10 / 10$ in OD and 2/10 in OS. Slit-lamp examination and intraocular pressure were normal in both eyes. While the right fundus was normal, there was a hard exudate plaque at the left macula associated with extensive peripheral retinal telangiectasia (fig. 3a). Fluorescein angiography showed wide areas of peripheral retinal nonperfusion and classic lightbulb type hyperfluorescent vascular dilatations (fig. 3b). Optical coherence tomography (OCT) exhibited serous macular detachment (fig. 3c). Our diagnosis was stage 3a Coats' disease. Therapeutic options and visual prognosis were discussed with the family, and we decided to proceed with indirect laser photocoagulation and a simultaneous intravitreal 0.7-mg dexamethasone implant injection. Under general anesthesia, indirect laser photocoagulation was performed in nonperfused areas and capillary dilations, and an intravitreal Ozurdex injection was given (fig. 4a). At week 6 after injection, the intraocular pressure was $28 \mathrm{~mm} \mathrm{Hg}$ and timolol maleate and brinzolamide combination was prescribed twice a day. At 3 months after injection, the intraocular pressure was $15 \mathrm{~mm} \mathrm{Hg}$ and antiglaucomatous medication was stopped. At 6 months after injection, visual acuity was 3/10 in OS and macular exudates were gradually resolving with no serous macular detachment (fig. $4 \mathrm{~b}$ and c).

\section{Discussion}

Two pathological processes are evident in Coats' disease [5]. The first consists of a breakdown of the blood-retina barrier at the endothelial level, which causes plasma leakage into the vessel wall and thickening of parts of the vessel wall, becoming necrotic and disorganized producing a sausage-like shape of the vessels. The second concerns the presence of abnormal pericytes and endothelial cells in the retinal blood vessels, which 
Saatci et al.: Intravitreal Dexamethasone Implant (Ozurdex) in Coats' Disease

subsequently degenerate. This causes abnormal retinal vasculature and the formation of aneurysms as well as vessel closure of, leading to ischemia.

Some investigators have demonstrated an increased level of VEGF in eyes with Coats' disease and a significant decrease in VEGF after the injection of anti-VEGF agents [6, 7]. Sun et al. [6] showed an elevated VEGF level in Coats' disease, which rapidly decreased from 908 $\mathrm{pg} / \mathrm{ml}$ to $167 \mathrm{pg} / \mathrm{ml}$ after the injection of pegaptanib sodium. He et al. [7] quantified the VEGF level in four eyes with Coats' disease (stage 2 or stage 3 disease; mean 2,394.5 pg/ml) and compared it with the VEGF levels in five eyes with rhegmatogenous retinal detachment (mean $15.3 \mathrm{pg} / \mathrm{ml}$ ). They noted a VEGF reduction from $1,247 \mathrm{pg} / \mathrm{ml}$ to $20.4 \mathrm{pg} / \mathrm{ml}$ in one eye treated with a single injection of bevacizumab. In another study, immunoreactivity for VEGF and VEGFR-2 in macrophages and endothelium of abnormal vessels in nine enucleated eyes with Coats' disease was demonstrated [8]. Intravitreal corticosteroid treatment can be considered in the treatment of Coats' disease as corticosteroids are well known to reduce intraocular inflammation, tighten capillary walls and suppress cell proliferation in addition to their anti-VEGF properties. Bergstrom and Hubbard [9] showed that a single 4-mg intravitreal triamcinolone injection reduced the subretinal fluid in all 5 patients who presented with bullous exudative retinal detachment secondary to Coats' disease and facilitated subsequent cryoablation in 4 of them. However, 3 patients developed cataract, 4 had an elevated intraocular pressure requiring antiglaucomatous medication and three eyes developed inoperable retinal detachment. Othman et al. [10] treated 15 Coats' disease cases with intravitreal triamcinolone injections at presentation and followed the patients for a minimum of 1 year. Eight cases already presented with total exudative retinal detachment. In 13 cases, peripheral laser ablation and/or cryotherapy were performed 1 month following the triamcinolone injection. The development of glaucoma in a single case and cataract in 6 of 15 cases $(40 \%)$ could be attributed to triamcinolone. The authors believed that intravitreal triamcinolone acetonide was associated with the fast resorption of subretinal fluid and exudates and helped the regression of the telangiectatic vessels so that the retina was more amenable to laser photocoagulation or cryotherapy. Ray et al. [11] compared their results with bevacizumab injections to those achieved with triamcinolone acetonide injections as an additional treatment modality to ablative therapy in eyes with Coats' disease. They argued that rapid resorption of subretinal fluid was seen after treatment with intravitreal triamcinolone, but this was not the case after bevacizumab injection.

Ozurdex is a biodegradable, sustained-release dexamethasone delivery system approved for the treatment of macular edema following retinal vein occlusion [12]. However, it is proven that its side effect profile is much better than that of intravitreal triamcinolone acetonide. Castillo et al. [13] reported a case of a 46-year-old female Coats' patient with a secondary vasoproliferative tumor. After dexamethasone implant injection, the retina was reattached and they subsequently treated the telangiectatic vessels with laser photocoagulation. No recurrence of exudates was evident at the end of a 12-month follow-up. The authors commented that Ozurdex might be an effective initial therapeutic approach for Coats' disease that triggers immediate response and provides subsequent visual improvement.

In the 2 cases described, we encountered mild-to-moderate temporary intraocular pressure elevation related to a dexamethasone implant. This implant seems to be a valuable tool supplementing laser photocoagulation as it necessitates fewer injections than anti-VEGF agents and thereby fewer procedures requiring general anesthesia in the pediatric population. 


\begin{tabular}{l|l}
\hline Case Rep Ophthalmol 2013;4:122-128 \\
\hline DOI: 10.1159/000355363 & $\begin{array}{l}\text { C 2013 S. Karger AG, Basel } \\
\text { www.karger.com/cop }\end{array}$ \\
\hline
\end{tabular}

Saatci et al.: Intravitreal Dexamethasone Implant (Ozurdex) in Coats' Disease

\section{References}

1 Shields JA, Shields CL, Honavar SG, Demirci H: Clinical variations and complications of Coats' disease in 150 cases: the 2000 Sanford Gifford Memorial Lecture. Am J Ophthalmol 2001;131:561-571.

2 Shields JA, Shields CL, Honavar SG, Demirci H, Cater J: Classification and management of Coats disease: the 2000 Proctor Lecture. Am J Ophthalmol 2001;131:572-583.

3 Reichstein DA, Recchia FM: Coats disease and exudative retinopathy. Int Ophthalmol Clin 2011;51:93-112.

4 Chaudhary KM, Mititelu M, Lieberman RM: An evidence-based review of vascular endothelial growth factor inhibition in pediatric retinal diseases: part 2. Coats' disease, best disease, and uveitis with childhood neovascularization. J Pediatr Ophthalmol Strabismus 2013;50:11-19.

5 Ghorbanian S, Jaulim A, Chatziralli IP: Diagnosis and treatment of Coats' disease: a review of the literature. Ophthalmologica 2012;227:175-182.

6 Sun Y, Jain A, Moshfeghi DM: Elevated vascular endothelial growth factor levels in Coats' disease: rapid response to pegaptanib sodium. Graefes Arch Clin Exp Ophthalmol 2007;245:1387-1388.

7 He YG, Wang H, Zhao B, Lee J, Bahl D, McCluskey K: Elevated vascular endothelial growth factor level in Coats' disease and possible therapeutic role of bevacizumab. Graefes Arch Clin Exp Ophthalmol 2010;248:1519-1521.

8 Kase S, Rao NA, Yoshikawa H, Fukuhara J, Noda K, Kanda A, Ishida S: Expression of vascular endothelial growth factor in eyes with Coats' disease. Invest Ophthalmol Vis Sci 2013;54:57-62.

9 Bergstrom CS, Hubbard GB 3rd: Combination intravitreal triamcinolone injection and cryotherapy for exudative retinal detachments in severe Coats' disease. Retina 2008;28:S33-S37.

10 Othman IS, Moussa M, Bouhaimed M: Management of lipid exudates in Coats' disease by adjuvant intravitreal triamcinolone: effects and complications. Br J Ophthalmol 2010;94:606-610.

11 Ray R, Barañano DE, Hubbard GB: Treatment of Coats' disease with intravitreal bevacizumab. Br J Ophthalmol 2013;97:272-277.

12 Haller JA, Bandello F, Belfort R Jr, Blumenkranz MS, Gillies M, Heier J, Loewenstein A, Yoon YH, Jacques ML, Jiao J, Li XY, Whitcup SM; Ozurdex Geneva Study Group: Randomized, sham-controlled trial of dexamethasone intravitreal implant in patients with macular edema due to retinal vein occlusion. Ophthalmology 2010;117:1134-1146.

13 Martinez-Castillo S, Gallego-Pinazo R, Dolz-Marco R, Marin-Lambíes C, Diaz-Llopis M: Adult Coats' disease successfully managed with the dexamethasone intravitreal implant (ozurdex ${ }^{\circledR}$ ) combined with retinal photocoagulation. Case Rep Ophthalmol 2012;3:123-127.

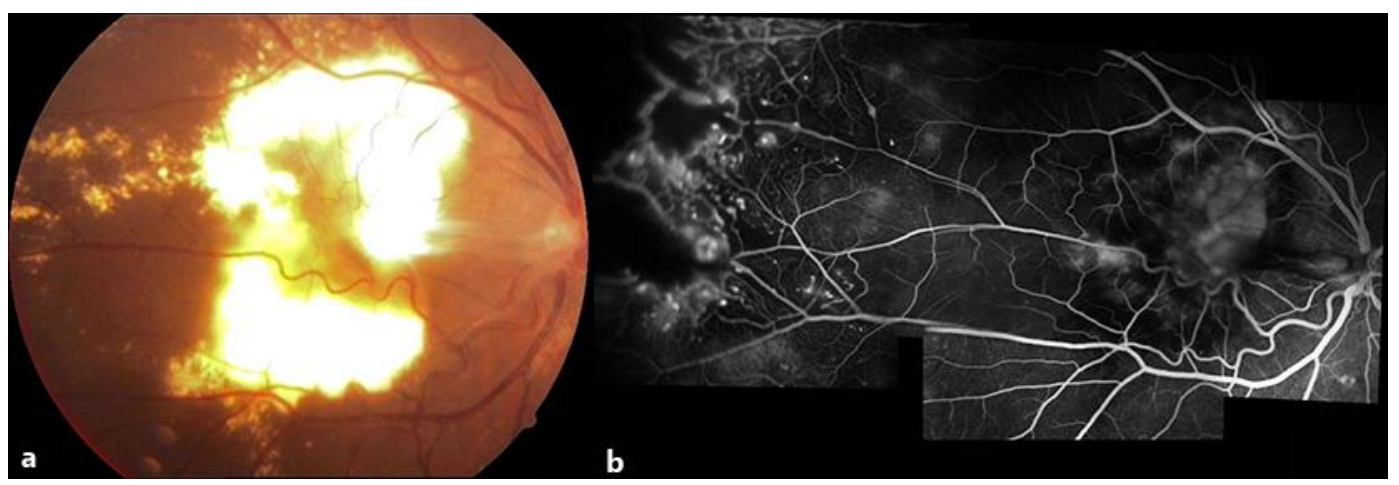

Fig. 1. a Case 1, OD, color fundus picture. Extensive macular exudation with a slight epiretinal membrane. b Composite fluorescein angiographic appearance showing wide areas of peripheral nonperfusion and dilated vessels with lightbulb hyperfluorescence. 
Case Reports in

Ophthalmology
Case Rep Ophthalmol 2013;4:122-128

DOI: $10.1159 / 000355363$

Saatci et al.: Intravitreal Dexamethasone Implant (Ozurdex) in Coats' Disease

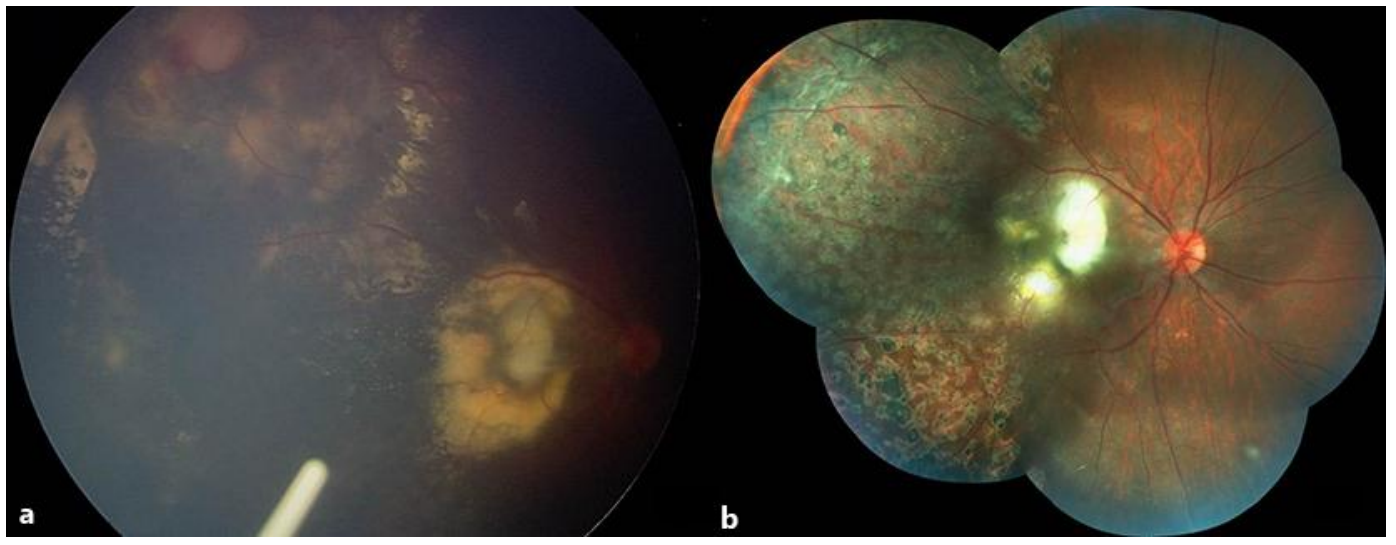

Fig. 2. a Case 1, OD, color RetCam 2 picture taken immediately after Ozurdex injection. b Composite color fundus picture depicting macular fibrosis and scattered laser photocoagulation scars. 
Case Reports in

Ophthalmology
Case Rep Ophthalmol 2013;4:122-128

DOI: $10.1159 / 000355363$

Saatci et al.: Intravitreal Dexamethasone Implant (Ozurdex) in Coats' Disease

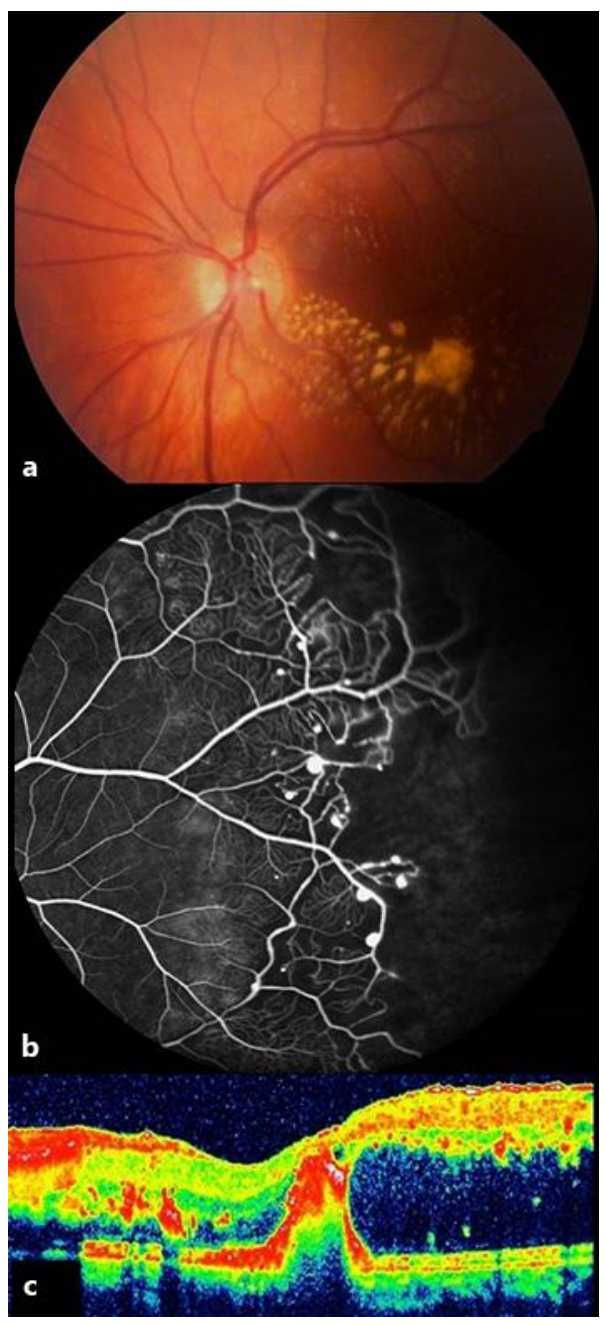

Fig. 3. a Case 2, OS, color fundus picture, macular exudation. b Temporal retina, fluorescein angiographic appearance showing peripheric retinal nonperfusion and capillary dilatations. c OCT showing serous detachment. 


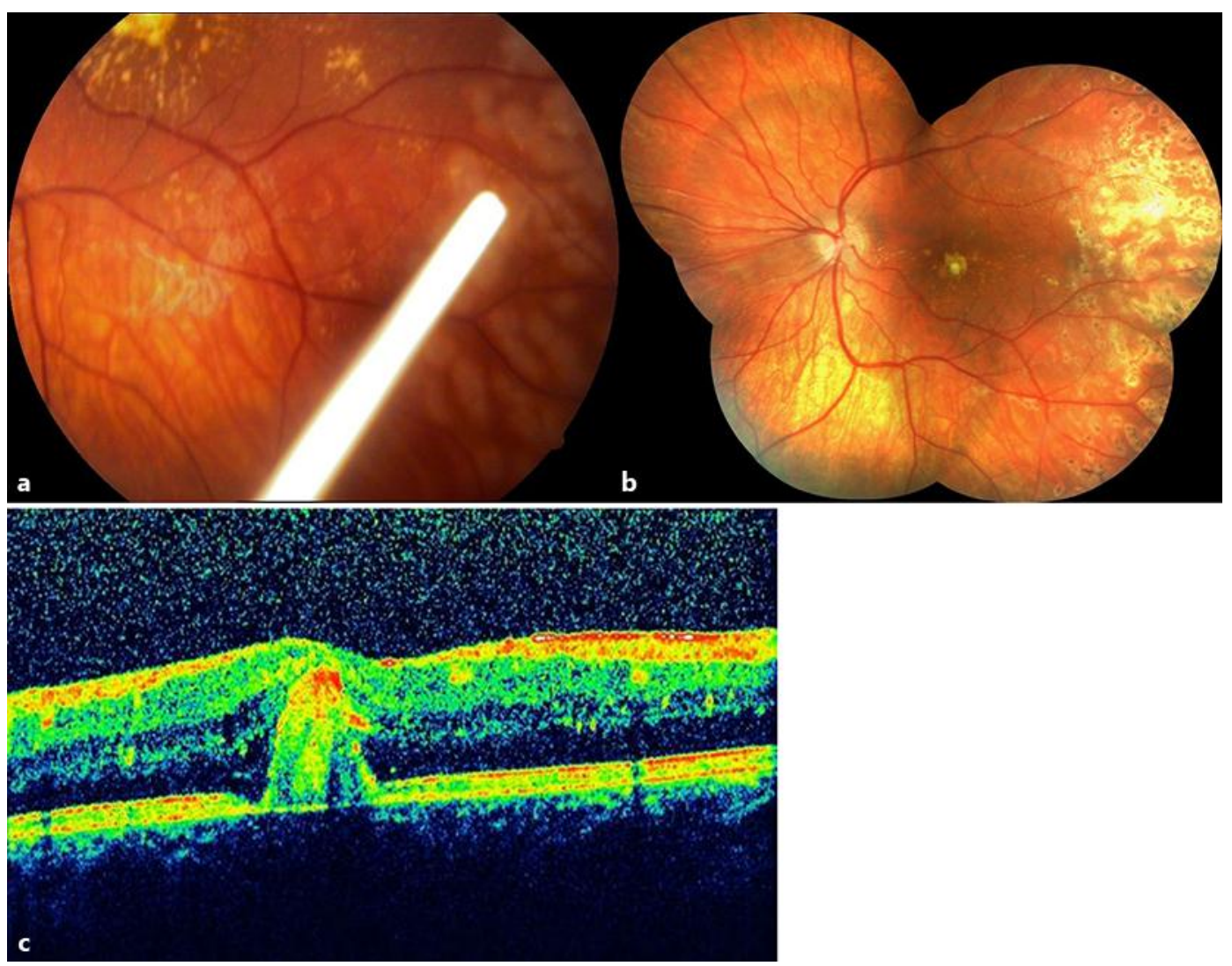

Fig. 4. a Case 2, OS, color fundus image taken after Ozurdex injection. b Composite color fundus picture demonstrating the relatively regressed macular hard exudates 6 months after indirect laser photocoagulation and Ozurdex injection. c OCT showing the resolution of the initial serous detachment with slight residual macular fibrosis. 